\title{
Statistical modeling of main cutting force produced by wet turning using soluble oil-water mixture lubricant
}

\author{
L B Abhang ${ }^{\mathrm{a}^{*}}$ and M Hameedullah ${ }^{\mathrm{a}}$
}

${ }^{a}$ Mechanical engineering department, Aligarh Muslim University, Aligarh, India

\begin{tabular}{|c|c|}
\hline A R T I C L E I N F O & A B S T R A C T \\
\hline $\begin{array}{l}\text { Article history: } \\
\text { Received } 15 \text { August } 2010 \\
\text { Received in revised form } \\
3 \text { December } 2010 \\
\text { Accepted } 3 \text { December } 2010 \\
\text { Available online } \\
4 \text { December } 2010 \\
\text { Keywords: } \\
\text { Cutting force } \\
\text { Response surface methodology } \\
\text { Metal cutting } \\
\text { Factorial design } \\
\text { Statistical modeling }\end{array}$ & $\begin{array}{l}\text { In this paper, we present machining tests by turning En-31 steel alloy with tungsten carbide } \\
\text { inserts using soluble oil-water mixture lubricant under different machining conditions. First- } \\
\text { order and second-order cutting force prediction models were developed by using the } \\
\text { experimental data by applying response surface methodology combined with factorial design of } \\
\text { experiments. Analysis of variance (ANOVA) is also employed to check the adequacy of the } \\
\text { developed models. The established equations show that feed rate and depth of cut are the main } \\
\text { influencing factors on the cutting force followed by tool nose radius and cutting velocity. It } \\
\text { increases with increase in the feed rate, depth of cut and tool nose radius but decreases with an } \\
\text { increase in the cutting velocity. The predicted cutting force values of the samples have been } \\
\text { found to lie close to that of the experimentally observed values with } 95 \% \text { confident levels. } \\
\text { Moreover, the surface response counters have been generated from the model equations. } \\
\text { Desirability function is used for single response optimization. }\end{array}$ \\
\hline
\end{tabular}

\section{Introduction}

Turning process is one of the most important process used for machining elements constructions in metal cutting industries, workshop practice, automobile, shipping and aerospace etc, for applications carried out in conventional machine tools as well as NC, CNC machine tools, machining centers and related manufacturing systems. At turning process, the work piece material is rotated and the cutting tool, travelling to the left, removes a surface layer in the form of chips of the work piece material, producing three cutting force components as shown in Fig.1. These are the main cutting force (Fc) (Thrust force), which acts on the cutting speed direction, the feed force (Ff), which acts on the feed rate direction and radial force (Fr), which acts on the radial direction and is normal to the cutting

* Corresponding author. Tel./fax: + 09286015515

E-mail addresses: abhanglb@yahoo.co.in (L. B. Abhag) 
speed or along the tool direction. The knowledge of the cutting force is essential for the following reasons:

1. Proper design of the machine tools

2. Proper design of the fixtures used to hold the work piece and cutting tool

3. Calculation of the machine tool power and power requirements is essential to choose a machine tool with adequate power

Out of three force components, the cutting force (main force) constitutes about $70 \%$ to $80 \%$ of the total force (Bhattacharyya, 1996, Kalpakjian, 1997). Further, their prediction helps in the analysis of optimization problems in machining economics in adaptive control applications, in the formulation of simulation models in machining database and planning the machining (production) process.

There are many issues associated with machining conditions that help understand the metal cutting mechanisms. These items include: the knowledge of machining conditions such as cutting velocity, feed rate, depth of cut, tool geometry such as tool rake angles, approach angle, tool materials, tool nose radius and coated or uncoated type tools, mechanical and physical properties of work material and tool materials, chemical composition of work piece material on the generated cutting forces. In metal machining mechanisms mainly consists of machinability of work materials, wear (flank and crater) resistance of tool materials during machining, chip formation process (types of chips), tool materials, the frictional and thermal properties at chip-tool interface during machining.

Several criteria may be used to evaluate machinability, but the most important are tool life, cutting forcess, metal cutting power, specific cutting pressure and surface roughness (Davim et al., 2004). Cutting force analysis plays a vital role in studying various characteristics of a machining process, for instance, the dynamic stability, positioning accuracy of the tool and roughness of the machined surface (Wang et al., 1980). Allauddin et al., (1998) investigated the effect of cutting speed, feed rate and axial depth on cutting force. According to Chen (2000), during finishing operation of hardened steel, radial thrust, force became largest among three cutting force components and it was most sensitive to changes of cutting edge chamfer, tool nose radius and flank wear. Chandra et al. (2000) monitored the cutting force and power consumed in a turning operation for a tool in good condition until it approached its maximum flank wear. They carried out an experimental investigation on mild steel to correlate the rise in cutting force and power expended with the tool wear rate to propose a suitable methodology for estimating tool wear. Tests were carried out on mild steel using a carbide tipped tool. The results indicated a significant increase in the cutting forces and power as the tool wear progressed in a continuous turning operation. It was possible to the predict tool wear more precisely by continuously monitoring the cutting forces, power, and current for all machining conditions. It was observed that the cutting forces are directly dependent on the machining parameters and tool geometry i.e. cutting speed, feed rate, depth of cut, rake angle, approach angle, work piece material type, tool material type and lubricant/coolant type (Lin et al., 2001, Gunay et al., 2005; Petropoulos et al., 2005; Luo et al., 1998). Cutting forces are mainly affected by cutting velocity, feed rate, undeformed chip thickness, cutting tool material, approach angle, rake angle, depth of cut and tool wear (Kalpakjian, 1997; Oraby et al., 2004).

EN-31 is a carbon steel alloy and finds its typical applications in the manufacturing of machine tool parts like spindles, shafts, bearings and automobile products. Properties of EN-31 steel alloy, like low specific heat, tendency to high strain harden and diffuse between tool and work material, give rise to certain problems in its machining such as high chip-tool interface temperature, large cutting forces, poor quality of surface finish and built-up-edge formation. This material is thus difficult to machine (Shaw, 1998, Komanduri, 1982) investigated the machining of En-31 steel with high speed tool steels. They found large forces during machining which may result in tool factor and high cutting temperatures. Lo et al. (1987) studied tool life in direct current hot machining of En-24 steel using carbide tools in the speed range of $35-230 \mathrm{~m} / \mathrm{min}$. They used response surface methodology for design of experiments. Owing to its wide application, En-31 steel alloy is selected as the work material in this case study. Recently developed tool materials such as tungsten carbide tools have improved productivity of such type of work materials (EN-31 steel). The tungsten carbide cutting tool 
is ideal for finishing to general machining of most work piece materials at higher cutting speeds. Carbide tools have good resistance to wear, thermal shock and corrosion. Excellent for machining most steels, stainless steel, cast iron, nonferrous materials and alloys under stable conditions. It also performs well machining hardened and short chipping materials. The literature survey reveals that the machining of En-31 steel alloy materials is relatively a less researched area. There is also a complete dearth of interaction studies. The objective of this study is to obtain optimal settings of machining process parameters i.e. cutting velocity, feed rate, depth of cut and tool nose radius, to yield optimal main cutting force while machining En-31 steel alloy with tungsten carbide tools under wet machining.

The optimization of process parameters requires a systematic methodological approach by using experimental methods and mathematical or statistical models. Statistical design of experiments based on factorial design with four added centre points (composite design)( Montgomery, 1991, Box, 1978) not only reduces the cost but also gives the required information about the main and interaction effect on the response parameters. There are numerous advantages associated with the use of factorial design in conducting experiments. It is more efficient than the conventional one-factor-at-a-time, experiments and it enables the study of both, the main and interaction effects among the factors. A parameter, say cutting forces, needs to be minimized with respect to the combination factors; factorial design with eight added centre points will give combination near to the minimum or maximum whereas the one-factors-at-a-time procedure will not.

In the present study, experimental investigation are conducted by turning En-31 steel alloy with tungsten carbide cutting tool using soluble oil-water mixture lubricant under different conditions of cutting speed, feed rate, depth of cut and tool nose radius. Cutting force values are recorded and statistically analyzed by Minitab software (MINITAB-15, 2007). The first and the second order cutting force prediction models are developed and reported. In addition, counters for each of the response surface at different cutting parameters are plotted. These response counters can help the prediction of the surface roughness at any machining zone of the experimental domain.

\section{Response surface method}

Response surface method (RSM) is a collection of statistical and mathematical methods that are useful for the modeling and optimization of the engineering problems. The present study takes into account the simultaneous variation of cutting speed, feed rate, depth of cut and tool nose radius and predicts the cutting force (response) and the approach is known as RSM. Factorial designs are used widely in experiments involving several factors on a response. The meaning of factorial design is that each complete test or replications of all the possible combinations of the levels of the factors are investigated (Montogomery, 1991; Box, 1978).

Factorial design with eight added centre points $(24+8)$ used in this work is a composite design, originally proposed by Box (1978). There are numerous advantages associated with the use of factorial design in conducting experiments.

The proposed linear model correlating the responses and independent variable can be represented by the following equation.

$Y=m($ cutting speed $)+n \times($ feed rate $)+p \times($ depth of cut $)+q \times($ tool nose radius $)+e$,

where, $Y$ is the response, $e, m, n, p$ and $q$ are the constants. Eq. (1) can be written in the following form.

$Y=\Phi(v, f, d, r)+\varepsilon$

$Y_{1}=\beta_{0} x_{0}+\beta_{1} x_{1}+\beta_{2} x_{2}+\beta_{3} x_{3}+\beta_{4} x_{4}$

where $Y_{1}$ is the response, $x_{0}=1$ (dummy variables), $x_{1}=$ cutting speed, $x_{2}=$ feed rate, $x_{3}=$ depth of cut and $x_{4}=$ tool nose radius. Also $\beta_{0}=c$ and $\beta_{1}, \beta_{2}, \beta_{3}$ and $\beta_{4}$ are the model parameters. The general second order model can be expressed as follows, 
$Y_{2}=\beta_{0} x_{0}+\beta_{1} x_{1}+\beta_{2} x_{2}+\beta_{3} x_{3}+\beta_{4} x_{4}+\beta_{12} x_{1} x_{2}+\beta_{23} x_{2} x_{3}+\cdots$

where, $Y_{2}$ is the estimated response based on second order equation. The parameters $\beta_{0}, \beta_{1}, \beta_{2}, \beta_{4}$ and $\beta_{i j}, i, j=1, \cdots 4$ are to be calculated by the method of least squares. Hence the $\beta$ values can be determined by using Eq. (5).

The variables were coded by taking into account the capacity and the limiting cutting conditions of the lathe machine. The coded values of variables to be used in Eq. (3) and Eq. (4) were outlined from the following transforming equations.

$x_{1}=(\ln V-\ln 112) /(\ln 112-\ln 39)$

$x_{2}=(\ln F-\ln 0.10) /(\ln 0.10-\ln 0.06)$

$x_{3}=(\ln D-\ln 0.40) /(\ln 0.4-\ln 0.2)$

$x_{4}=(\ln R-\ln 0.8) /(\ln 0.8-\ln 0.4)$

where $x_{1}$ is the coded value of cutting speed V, $x_{2}$ is the coded value of feed rate F, $x_{3}$ is the coded value of depth of cut $\mathrm{D}$, and $x_{4}$ is the coded value of tool nose radius $\mathrm{R}$. The following null hypotheses have been considered.

$H_{0}: \beta_{i}=\beta_{i j}=0, i=1, \cdots, 4$

That is to say that none of the factors viz cutting speed, feed rate, depth of cut, and tool nose radius have a significant influence on the cutting force.

\section{Experimental set-up and cutting condition Experiments}

The experiments are carried out on HMT heavy duty lathe machine (LTM-20) as shown in Fig.1.

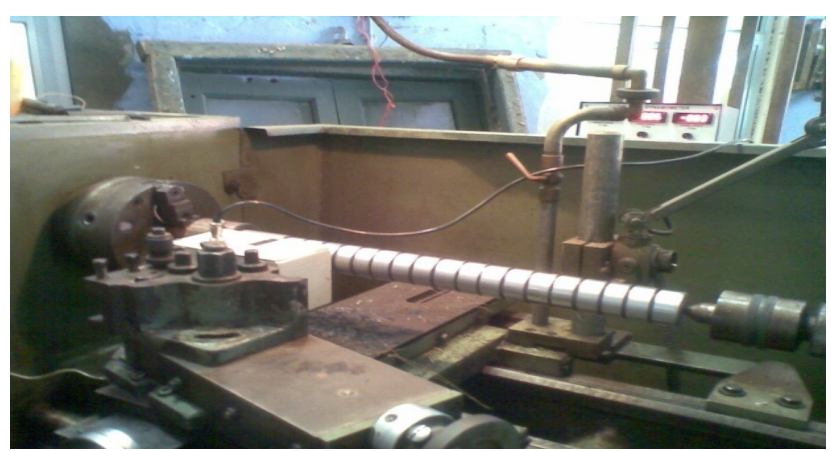

Fig.1. Experimental set-up on HMT heavy duty Lathe Machine

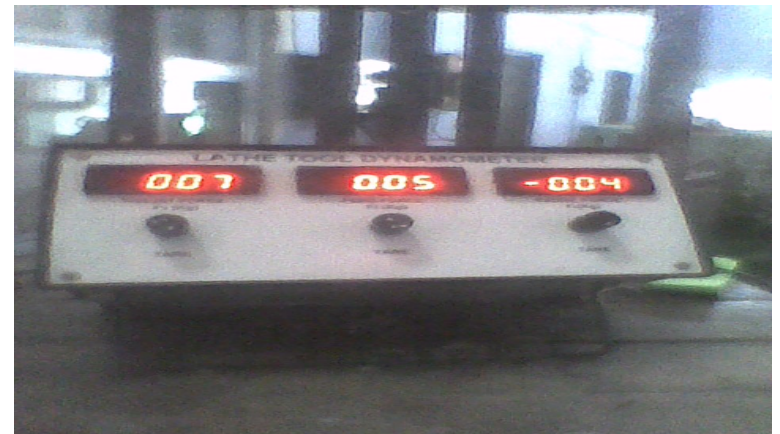

Fig. 2. Lathe tool dynamometer for measuring main cutting force

Total 24 experiments are carried out with soluble oil lubricant. Soluble oil (Koolkut-40, a product of Hindustan petroleum, emulsified oil, emulsion strength 5-10\% with water in the ratio of 1:20) coolant was used in this experiment. Water was added into the coolant until the mixture of coolant and water reaches the $\mathrm{pH}$ ranges from 9.0 to 9.5. A commercial alloy steel work-piece (EN-31) is machined on HMT lathe. Table 1, Table 2 and Table 3 show chemical composition of work piece material, three levels of factors and the factorial design of experimentation, respectively. The complete design consist of 24 experiments. This method classifies and identifies the parameters to three different levels (i.e. low, centre and high) as shown in Table 1 the work piece material used has a dimension of $400 \mathrm{~mm}$ in length and $50 \mathrm{~mm}$ in diameter. The cutting tool holder used for turning operation is WIDAX tool holder SCLCR 12.12 Fog 13 and diamond shape carbide (CNMA 1204-04,

CNMA 120408 and CNMA 1204 12). [ $\alpha=60, \mathrm{Vo}=-60, \lambda_{6}=-60, \mathrm{Kr}=950, \quad \in \mathrm{r}=80 \mathrm{o}, \mathrm{r}=0.4$, $0.8,1.2 \mathrm{~mm}]$. 
This material is suitable for a wide variety of automotive type applications like axle, roller bearings, ball bearings, shear blades, spindle, mandrels, forming and molding dies, rollers, blanking and forming tools, knurling-tools and spline shafts are the examples of automotive components produced using this material where the turning is the prominent machining process used. The process variables or control variables such as cutting speed, feed rate, depth of cut and tool nose radius are identified to carry out the experiments and to develop the statistical empirical models. In this investigation, the cutting force was measured using lathe Tool Dynamometer (strain gauge type three components lathe tool dynamo meter) as shown in Fig. 2 and cutting forces were recorded during turning as shown in Table 3. The statistical analysis of the data was carried out in two steps, first analysis of variance (ANOVA) was performed to study the contribution of the factors and the interactions and secondly, multiple correlation models were developed for the cutting force components. Also, response surface methodology was used to quantify relationships among one or more measured response variables (the cutting force components) and the vital input factors i.e. metal cutting conditions and tool geometry (tool nose radius ).

\section{Table 1}

Chemical composition of alloy steel (EN-31steel)

\begin{tabular}{llllllll}
\hline Composition & $\mathrm{C}$ & $\mathrm{Si}$ & $\mathrm{Mn}$ & $\mathrm{Cr}$ & $\mathrm{Co}$ & $\mathrm{S}$ & $\mathrm{P}$ \\
\hline Wt. \% & 0.95 & 0.10 & 0.30 & 1 & 0.025 & 0.04 & 0.04 \\
\hline
\end{tabular}

Table 2

Three levels of variables and coding identification

\begin{tabular}{ccccccccc}
\hline Levels & $\mathrm{V}(\mathrm{m} / \mathrm{min})$ & $\mathrm{F}(\mathrm{mm} / \mathrm{rev})$ & $\mathrm{D}(\mathrm{mm})$ & $\mathrm{R}(\mathrm{mm})$ & $x_{1}$ & $x_{2}$ & $x_{3}$ & $x_{4}$ \\
\hline Low & 39 & 0.06 & 0.2 & 0.4 & -1 & -1 & -1 & -1 \\
Middle & 112 & 0.10 & 0.4 & 0.8 & 0 & 0 & 0 & 0 \\
High & 189 & 0.15 & 0.6 & 1.2 & +1 & +1 & +1 & +1 \\
\hline
\end{tabular}

Table 3

Design Matrix

\begin{tabular}{lccccc}
\hline Sr. No & $X_{1}$ & $X_{2}$ & $X_{3}$ & $X_{4}$ & Response Fc (N) \\
\hline 1 & -1 & -1 & -1 & -1 & 166.77 \\
2 & -1 & -1 & -1 & +1 & 176.00 \\
3 & -1 & -1 & +1 & -1 & 220.06 \\
4 & -1 & -1 & +1 & +1 & 216.00 \\
5 & -1 & +1 & -1 & -1 & 243.04 \\
6 & -1 & +1 & -1 & +1 & 294.00 \\
7 & -1 & +1 & +1 & -1 & 317.00 \\
8 & -1 & +1 & +1 & +1 & 145.38 \\
9 & +1 & -1 & -1 & -1 & 206.23 \\
10 & +1 & -1 & -1 & +1 & 235.00 \\
11 & +1 & -1 & +1 & -1 & 200.00 \\
12 & +1 & -1 & +1 & +1 & 261.42 \\
13 & +1 & +1 & -1 & -1 & 301.00 \\
14 & +1 & +1 & -1 & +1 & 227.10 \\
15 & +1 & +1 & +1 & -1 & 231.00 \\
16 & +1 & +1 & +1 & +1 & 215.00 \\
17 & 0 & 0 & 0 & 0 & 223.70 \\
18 & 0 & 0 & 0 & 0 & 221.00 \\
19 & 0 & 0 & 0 & 0 & 219.98 \\
20 & 0 & 0 & 0 & 0 & 224.00 \\
21 & 0 & 0 & 0 & 0 & \\
22 & 0 & 0 & 0 & 0 & 00 \\
23 & 0 & 0 & 0 & 0 & 0 \\
24 & 0 & 0 & 0 & 0 & \\
\hline
\end{tabular}




\section{Table 4}

Analysis of variance for first-order cutting force model

\begin{tabular}{lccccc}
\hline Source & DF & SS & MS & F & P \\
\hline Regression & 4 & 36689.5 & 9172.4 & 264.18 & $0.000 \mathrm{~s}$ \\
Linear & 4 & 36689.5 & 9172.4 & 264.18 & $0.000 \mathrm{~s}$ \\
Residual error & 19 & 659.7 & 34.7 & - & - \\
Lack-of-fit & 12 & 469.00 & 39.10 & 1.43 & $0.325 \mathrm{Ns}$ \\
Pure error & 7 & 190.7 & 27.7 & - & - \\
Total & 23 & 37349.10 & - & - & - \\
\hline
\end{tabular}

DF, degree of freedom, SS, sum of squares, MS, mean square, Ns, not significant, s, significant, F, f-value, P, P-value

\section{Table 5}

Analysis of variance for second t-order cutting force model

\begin{tabular}{lccccc}
\hline Source & DF & SS & MS & F & P \\
\hline Regression & 11 & 37072.0 & 3370.182 & 145.93 & $0.000 \mathrm{~s}$ \\
Linear & 4 & 36689.5 & 416.384 & 18.03 & $0.000 \mathrm{~s}$ \\
Square & 1 & 8.6 & 8.576 & 0.37 & $0.554 \mathrm{Ns}$ \\
Interaction & 6 & 373.9 & 62.318 & 2.70 & $0.068 \mathrm{~s}$ \\
Residual error & 12 & 277.1 & 23.094 & - & - \\
Lack-of-fit & 5 & 86.4 & 17.284 & - & $0.681 \mathrm{Ns}$ \\
Pure error & 7 & 190.7 & 27.245 & - & - \\
Total & 23 & 37349.1 & - & - \\
\hline
\end{tabular}

\section{Table 6}

Constraints used for optimization

\begin{tabular}{|c|c|c|c|c|c|}
\hline Name of parameters & Goal & Lower limit & Upper limit & Weight & Weight \\
\hline Cutting speed & is in range & 39 & 189 & 1 & 1 \\
\hline Feed rate & is in range & 0.06 & 0.15 & 1 & 1 \\
\hline Depth of cut & is in range & 0.2 & 0.6 & 1 & 1 \\
\hline Nose radius & is in range & 0.4 & 1.2 & 1 & 1 \\
\hline Cutting force & minimize & 145.30 & 317.0 & 1 & 1 \\
\hline
\end{tabular}

\section{Table 7}

Optimal setting and confirmation runs showing results for the main cutting force $(N)$

\begin{tabular}{llllllll}
\hline $\begin{array}{l}\text { Run } \\
\text { No. }\end{array}$ & $\begin{array}{l}\text { Speed } \\
\mathrm{m} / \mathrm{min}\end{array}$ & $\begin{array}{l}\text { Feed } \\
\mathrm{Mm} / \mathrm{rev}\end{array}$ & $\begin{array}{l}\text { Depth of cut } \\
\mathrm{mm}\end{array}$ & $\begin{array}{l}\text { Nose radius } \\
\mathrm{mm}\end{array}$ & $\begin{array}{l}\text { Exp. } \\
(\mathrm{N})\end{array}$ & $\begin{array}{l}\text { Pred. } \\
(\mathrm{N})\end{array}$ & Desirability \\
\hline 1 & 189 & 0.06 & 0.2 & 0.4 & 145.52 & 147.725 & 0.98587 \\
2 & 112 & 0.06 & 0.2 & 0.4 & 156.09 & 154.147 & 0.94847 \\
3 & 189 & 0.06 & 0.2 & 0.8 & 158.38 & 160.554 & 0.9110 \\
4 & 189 & 0.06 & 0.2 & 1.2 & 175.62 & 173.34 & 0.8360 \\
\hline
\end{tabular}

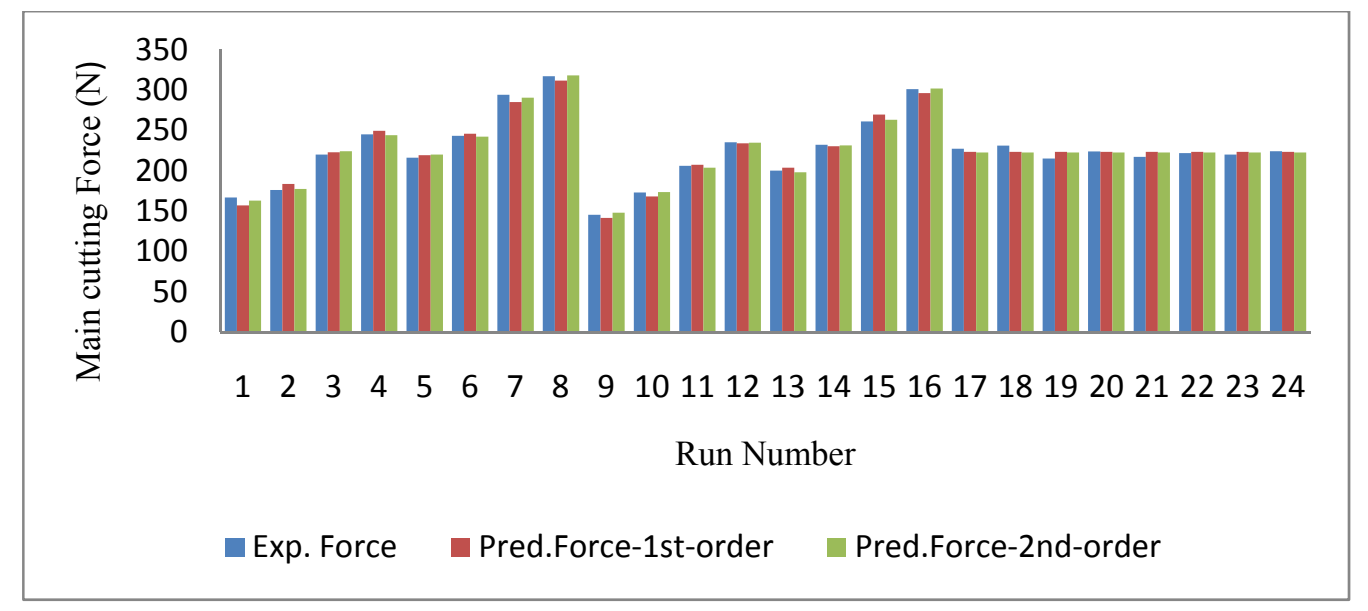

Fig.3. Comparison of measured and predicted cutting force $(\mathrm{N})$ 


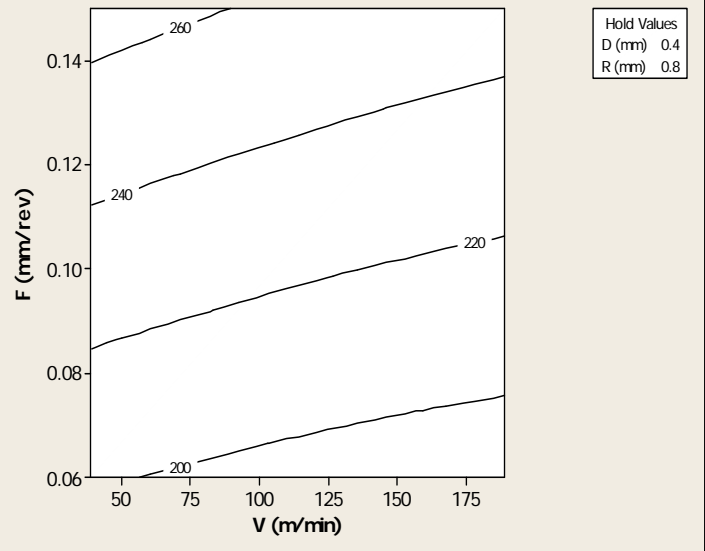

Fig. 4 a. Cutting force counters in cutting speed-feed plane for depth of cut and nose radius at ( $0.4 \mathrm{~mm}$ and $0.8 \mathrm{~mm}$ )

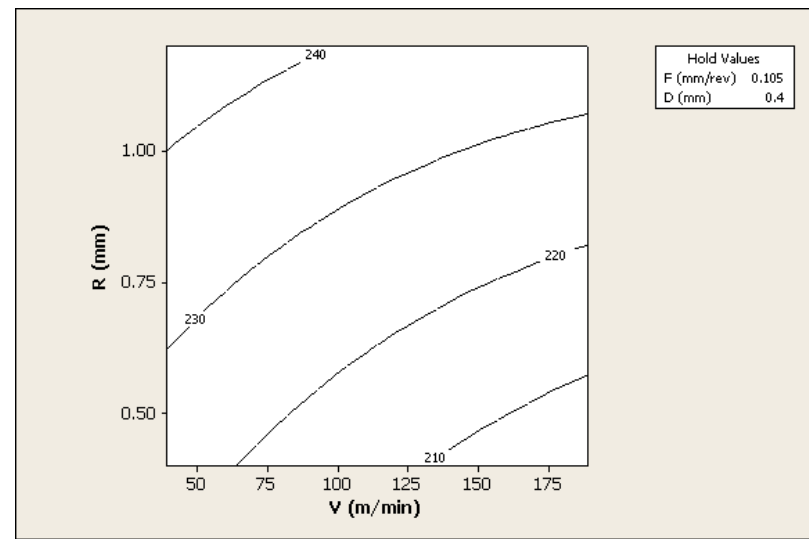

Fig. 4c. Cutting force counters in nose radius -cutting speed plane for feed rate and depth of cut at $(0.10 \mathrm{~mm} / \mathrm{rev}$ and $0.4 \mathrm{~mm}$ )

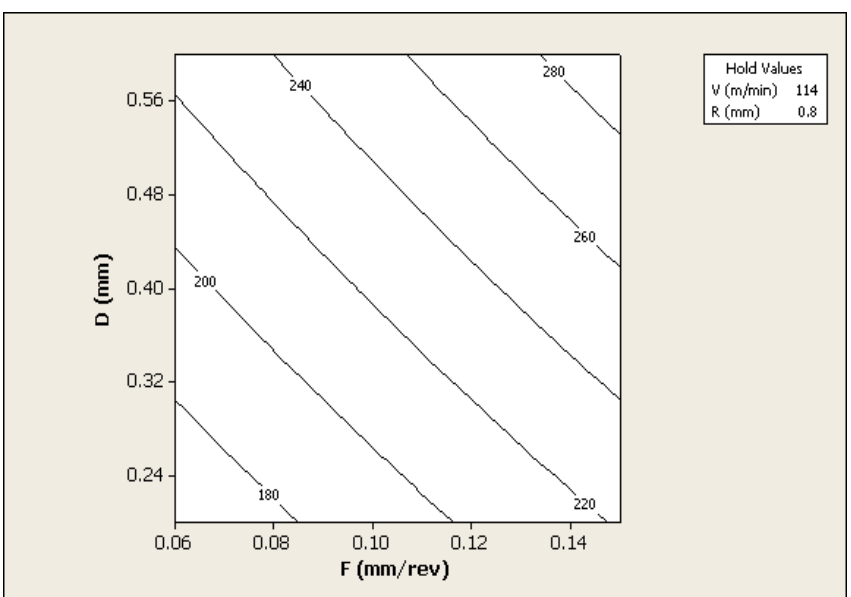

Fig. 4 b. Cutting force counters in Depth of cut -feed plane for cutting speed and nose radius at $(112 \mathrm{~m} / \mathrm{min}$ and $0.8 \mathrm{~mm})$

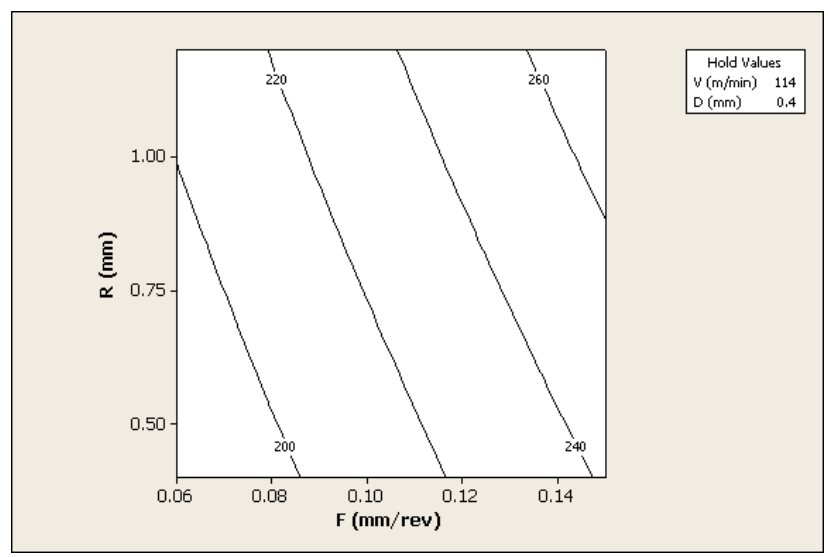

Fig. 4d. Cutting force counters in nose radius -feed plane for cutting speed and depth of cut at $(112 \mathrm{~m} / \mathrm{min}$ and $0.4 \mathrm{~mm})$

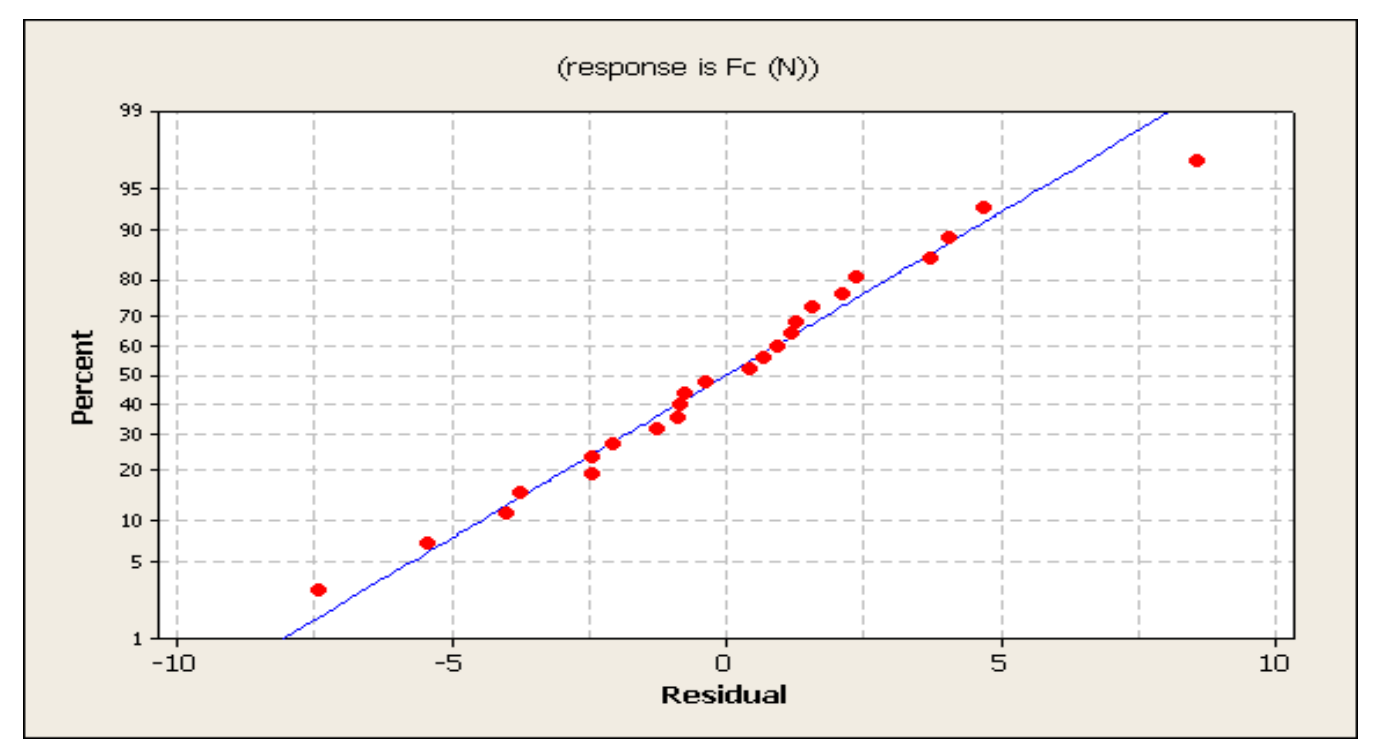

Fig. 5a. Normal probability plot of the residuals (response is Main cutting force) 


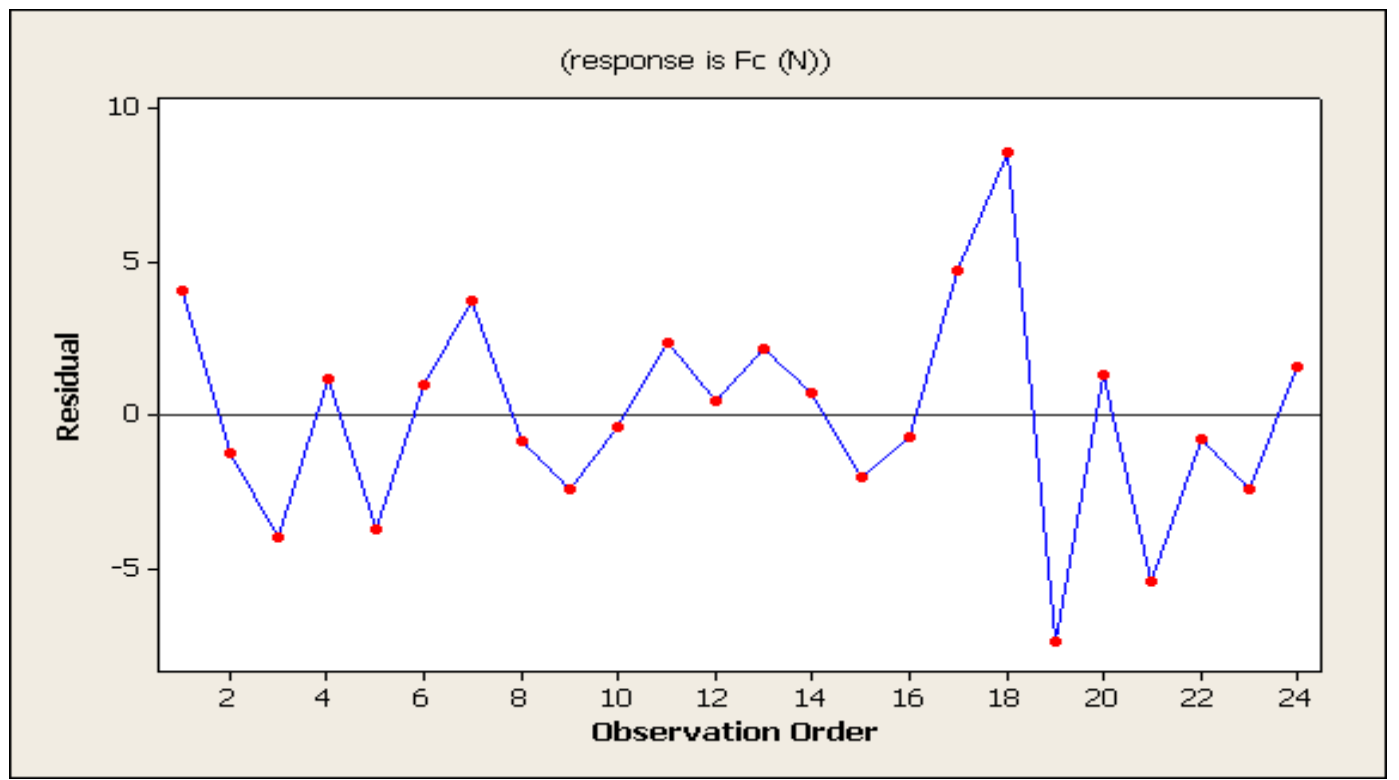

Fig. 5b. Residual versus order of the data (response is Main cutting force)

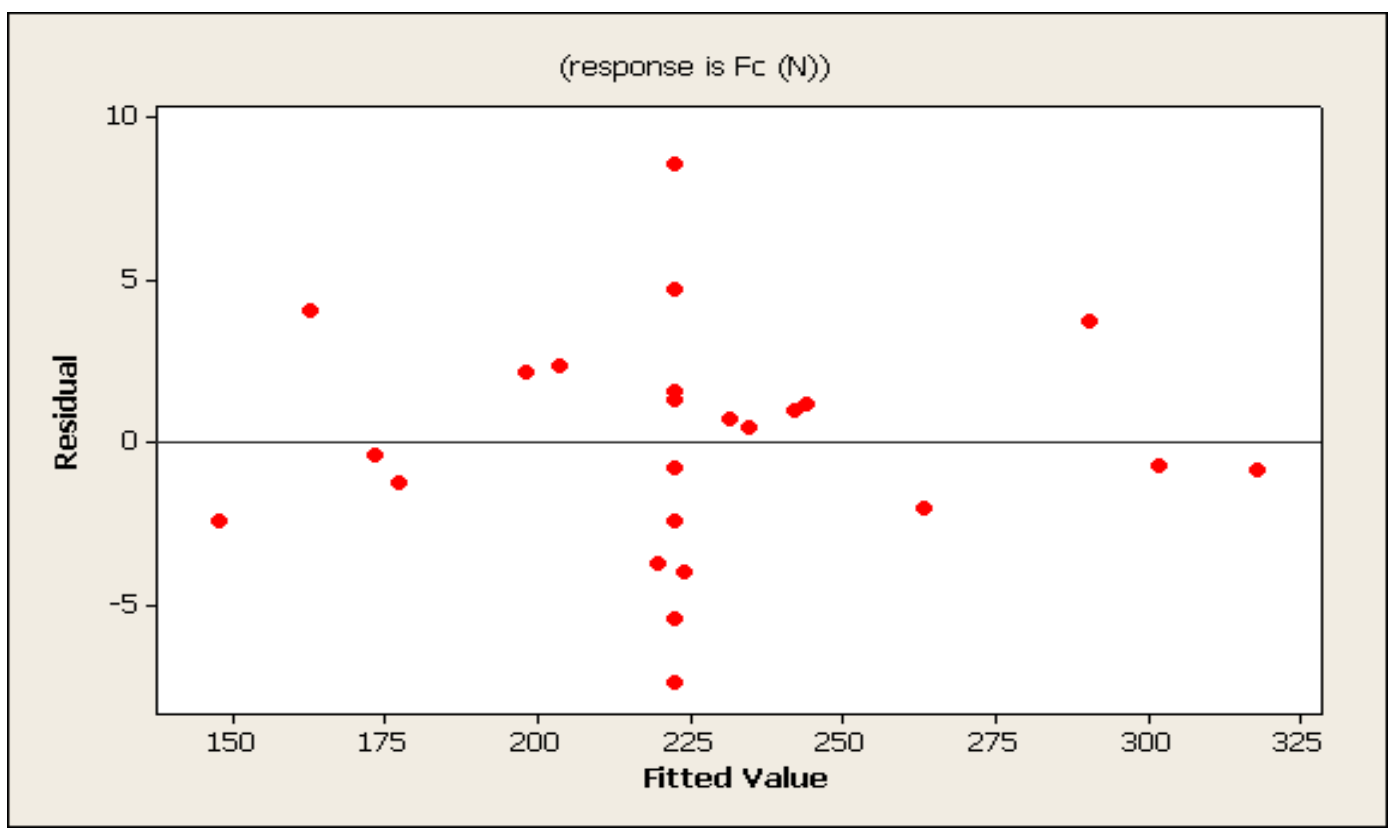

Fig. 5c. Residuals versus the fitted values (response is Main cutting force)

\section{Results and analysis}

A statistical software program, Minitab-15 and Microsoft excel (MS Office-2007) were employed in models training (MINITAB-15, 2007) and in statistics for analyzing significant effect of the parameters on the quality characteristics. For analysis of the data, we have to verify the goodness of fitted model. Model adequacy checking includes test for significance of regression model and on model coefficients, and test for lack-of-fit (Montgomery, 1991). Analysis of variance (ANOVA) is performed for this purpose.

\subsection{Development of the first and the second order cutting force model using RSM}

ANOVA reveals that the highest influence on cutting force is exerted by the depth of cut, feed rate and tool nose radius of varying order of contribution for main cutting force component i.e. thrust force, while the cutting speed has a less significant negative effect. This is desirable as it indicates 
that the terms in the model have significant effect on the response. The fit summary recommended that the first order and the second order models are statistically significant for analysis of cutting force at 95\% confidence level for having p-values less than 0.05 (Table 4-5) to represent relationship between the machining responses and the considered machining parameters of the steel turning process. The multiple regression coefficient of the second order model is $99.26 \%$. This means that the second order can explain the variation to extend of $99.26 \%$ that is greater than the multiple regression coefficient of the first order model, so it can be concluded that the second order mathematical model is more adequate to represent the En-31 steel turning process. Model F-value of 264.18 and 145.93 imply that both the first order and the second order models are significant. The second order model is also more significant as compared to the first order as shown in Fig.3. As seen from Fig. 3, the predicted cutting force using the second order RSM model is closely match with the experimental results. It exhibits the better agreement as compared to those from the first order RSM model. Lackof-fit is not significant relative to the pure error. There is a $68.10 \%$ chance that a large lack-of-fit value could occur due to noise. Non-significant lack-of-fit is good in the second order mathematical model, null hypothesis Ho is rejected and concluded that V, F, D and R have significant effect on cutting force $\mathrm{Fc}$, which implies that suggested models are adequate. Predicted $R^{2}$ of 0.9696 is in reasonable agreement with the adjusted $\bar{R}^{2}$ of 0.9858 (Table 5). This model can thus be used to navigate design space. Final response equations are as follows.

\subsubsection{First order model}

$F C=73.30-0.104 V+691 F+165 D+33.30 R$

Exponential model :

$$
F C=757.48\left(V^{-0.514} F^{0.299} D^{0.261} R^{0.100}\right) \text {. }
$$

Eq. (11) is derived from the Eq. (10) by substituting the coded values of $x_{1}, x_{2}, x_{3}$ and $x_{4}$ in terms of $\ln V, \ln F, \ln D, \ln R$.

\subsubsection{Second order model}

In order to see whether a second-order model can represent better than the first order or not, a second order model was developed. Note that we do not consider some of the terms in the second-order equations. Only significant parameters and their coefficients are included in the second-order equation and the remaining insignificant parameters are ignored. The student's t-test was applied to determine the significance and non-significance of these parameters and their coefficients. The second-order mathematical model is as follows,

$$
\begin{aligned}
F C & =98.879-0.14 V+559.022 F+134.693 D+4.797 R-0.510 V F-0.090 V D+0.093 V R \\
& +257.43 F D+107.882 F R+16.461 D R .
\end{aligned}
$$

where, $F c=$ main cutting force $(\mathrm{N}), V=$ cutting speed, $\mathrm{m} / \mathrm{min} ; F=$ feed rate, $\mathrm{mm} / \mathrm{rev}$; and $R=$ tool nose radius, $\mathrm{mm}$,

In this respect as it is seen from the model, feed rate and, depth of cut has the most significant effect over cutting force based on a 95\% confidence level, feed rate and depth of cut have a statistically significant impact on the cutting force since their $p$ values are smaller than $5 \%$ or equal to 0.000 . An increase in feed rate, depth of cut and tool nose radius will cause cutting force to become larger. On the other hand, a decrease in cutting speed will slightly cause a reduction in cutting force. Moreover, the interactions of feed rate and depth of cut and cutting speed and tool nose radius produces a statistically significant impact on the cutting force because their p-values are smaller than $5 \%$. The developed second-order mathematical model was used to plot counters of cutting forces at different values of machining parameters, namely cutting speed, feed rate, depth of cut and tool nose radius as 
shown in Fig.4 (a, b, c, and d). From the counter plot it is observed that any reduction in cutting speed and increase in feed rate, depth of cut and tool nose radius cause main cutting force increase dramatically as shown in Fig.4 (a,b,c and d). The cutting force reaches the highest when all machining conditions and their levels except for machining cutting velocity, are higher levels, as shown in Fig.4a.

The regression model is used to determining the residuals of each individual experimental run. The difference between the measured values and predicted values are called residuals. The residuals are calculated and ranked in ascending order. The normal probability plot of residuals for cutting force is shown in Fig 5a. The normal probability plot is used to vary the normality assumption. Fig. 5a shows that residuals are falling on a straight line, which means the errors are normally distributed. Hence it can be concluded that the experimental data of cutting force are normally distributed (Sidda et al., 2008). Fig. 5b shows the residuals against the observation order. Fig. 5b is used to show the correlation between the residuals. From the Fig. 5b, it is emphasized that a tendency to have runs of positive and negative residuals indicates the existence of a certain correlation. Also, the plot shows that the residuals are distributed evenly in both positive and negative along the experiment numbers. Hence, the data can be said to be independent. Fig.5c represents the residuals versus fitted responses for cutting force data, which shows only the maximum variation of 5 to 10 in cutting force between the measured and the fitted responses. It can be observed that no obvious patterns or unusual structure implying models are accurate.

\subsection{Optimization of cutting force value}

To improve the productivity, optimization of process parameters is an important criterion and there are different optimization techniques. In the present work, the response optimization analysis has been carried out to achieve the minimum cutting force in machining of EN-31 steel alloy using developed the second-order mathematical model. For optimizing the machining parameters desirability function based approach is used. In desirability function approach, the measured properties of each predicted response is transformed to a dimensionless desirability value $\mathrm{d}$. The scale of desirability function ranges between $d=0$, which suggests that the response is completely unacceptable, and $d=1$, which suggests that the response is exactly the target value. The value of $d$ increases as the desirability of corresponding response increases (Chorng, et al., 2008). Based on desirability-based approach one sided transformation is used to transform the response into a desirability value. In this study, the transformation of cutting forces is a smaller-the-better characteristics. The response is transformed into di:

$d=\left\{\begin{array}{lll}0 & \text { for } & \mathrm{y}>\mathrm{U} \\ 1 & \text { for } & \tilde{\mathrm{y}}>\mathrm{L}\end{array}\right.$

Let $\alpha$ be the weight and it is set to one since the di is important in this study, $\mathrm{L}$ and $\mathrm{U}$ are selected according to the mathematical model in response surface method.

The optimization analysis is carried out using Mini-Tab-14 software. In recent years, desirability function approach is used by some of the researchers to find the optimal solutions using multiperformance objective (Chorng et al., 2008). In the present work, single objective optimization is carried out using desirability based method. The optimization is carried out in two steps namely,

1) Obtaining the desirability for the response (main cutting force) and

2) The maximization of desirability and identifying the optimal values of parameters

The input parameters used and their limit and goal settings are given in Table 6. In desirability based approach, different solutions were obtained. The solution with high desirability is preferred. There are 24 solutions generated for getting the true optimal solution and the best solution is achieved based on the higher desirability. The results obtained from desirability function approach for the main cutting 
force with respect to different machining parameters and they are presented in Table7. In Table 7, the first run has been chosen as an optimal setting since it gives a maximized value of desirability by the desirability function approach. Furthermore, the best three solutions are simulated. The maximum desirability obtained in these cases is 0.98587 . The maximum desirability is attained at maximum cutting velocity and the minimum feed rate, depth of cut and tool nose radius. Based on the above criteria, the global solution is obtained for minimizing the main cutting force in machining of EN-31 steel alloy with tungsten carbide inserts and is given below:

Optimum value of cutting force $147.7256 \mathrm{~N}$ that corresponds to design variable is as follows,

cutting speed $189 \mathrm{~m} / \mathrm{min}$,

feed rate $0.06 \mathrm{~mm} / \mathrm{rev}$,

depth of cut $0.2 \mathrm{~mm}$ and

tool nose radius $0.4 \mathrm{~mm}$.

This is the minimum optimized value for selected range of variables parameters. It seems that the cutting velocity approaches to its maximum values and feed rate, depth of cue and tool nose radius to the minimum values. We emphasize that the optimum condition obtained in this study is only the near optimal solution. The computed values of above cutting speed, feed rate, depth of cut and tool nose radius are the best possible combinations within the selected range of parameters considered in this study.

\subsection{Validation of the optimal experimental results}

After identifying the most effective parameters, the final phase is to verify the regression models of the main cutting force by conducting confirmation experiments and comparing the results of these validation runs with respect to the model predicted values. According to Table 7, a cutting speed 189 $\mathrm{m} / \mathrm{min}$, a feed rate $0.06 \mathrm{~mm} / \mathrm{rev}$, depth of cut $0.2 \mathrm{~mm}$ and tool nose radius $0.4 \mathrm{~mm}$ are conducted. The predicted and experimental cutting force values are close with each other as shown in Table 7 . Those results yield about 3.5 to $4 \%$ errors between the predicted and the experimental data. Reasonable results are also obtained for the second and the third confirmation run (Table 7).

\subsection{The effect of machining conditions and tool nose radius on main cutting force}

The second-order mathematical models was used to predict the relationship between the cutting parameters and cutting force and the results are shown in Fig. 6 (a,b,c and d) for each response surfaces at three selected levels of cutting speed, feed rate, depth of cut and tool nose radius. It can be seen from the plots that the cutting force decreases with the increase in the cutting speed. The major effect on the cutting force is due to the feed rate, depth of cut followed by tool nose radius. As the feed rate, depth of cut and tool nose radius increases, cutting force also increases, whilst the rotational speed has a rather negligible influence. Fig. 6a shows the influence of cutting speed on the thrust (main) cutting force during metal cutting operation of En-31 steel work piece. The experimental results show that the cutting force is low at high cutting speed and comparatively high at low cutting speed. As the feed rate range increases from lower to higher range. The cutting force exhibit an almost linear increasing trend, independent of cutting speed. The reason for drop of cutting force with an increase of cutting speed is due to the decrease in chip thickness. This means, at higher speed, thinner chips are produced. It has also been suggested that the drop in these forces is partly caused by decrease in contact area of flow and partly by a drop in shear strength in the flow zone. As cutting speed increases the chips become thinner and shear angle increases thus decreasing chip reduction coefficient and chip strains, which means the plastic deformation of metal takes place with less strain because of greater shear angle, so the force and power consumption are low. The coefficient of friction decreases and consequently main cutting force decrease. On the other hand, cutting tool at high cutting force is severely damaged if compared with cutting tool at low cutting force. Cutting tool 
at low cutting force can continue more than one or two turns while cutting tool at high force cannot continue, since it get damaged at the first turn, when cutting force was higher. When cutting tool edge is not sharp enough, metal is pushed instead of cut, resulting in generating higher cutting forces and higher temperatures during machining of metals. At relatively high cutting velocity i.e. $189 \mathrm{~m} / \mathrm{min}$, cutting energy input to the machine tools and generated machining compressive stresses are correspondingly higher and lead to increased chip-tool interface temperatures (heat generation) (Trent, 1991). The generated heat in machining zone helps to soften work piece material, reducing cutting forces required to cut material. At higher cutting speeds $(189 \mathrm{~m} / \mathrm{min})$, built up edge formation disappears and chip-tool contact length decreases resulting in the reduction of cutting force and improvement in surface finish of the rotating work piece (Abhang et al., 2009). At lower cutting speeds $39 \mathrm{~m} / \mathrm{min}$ and $112 \mathrm{~m} / \mathrm{min}$, less chip-tool interface temperatures are generated and soften of work piece is minimized, giving rise to higher cutting forces. The predicted and measured trends show good overall agreement with the results obtained by Petropoulos (2005).

Fig. $6 \mathrm{~b}$ and Fig.6c show the effect of feed rate and depth of cut on the cutting force. The experimental results show that the cutting force is low at low feed rate and comparatively high at high feed rate. The experimental results reveal that cutting force is low at low depth of cut and comparatively higher at higher depth of cut. The greater the feed and depth of cut, the larger the cross-sectional area of the uncut chip and the volume of the deformed metal. Consequently, the greater is the resistance of the material to chip formation and the larger is the cutting force.

The experimental results reveal that the cutting force is low at low nose radius and comparatively high at high nose radius as shown in Fig.6d. During machining with a tool that has a large tool nose radius, a large part of the chip will have a chip thickness less than the minimum chip thickness value. In addition, increasing the nose radius has direct effect on main cutting force, leading to a significant increase in the plugging effect in the machining zone. Increasing the plugging effect leads to more material side flow on the machined surface. The smaller tool nose radius gives larger uncut chip thickness, thus greater shear plane heat source. An increase in tool nose radius increases deformation and hence larger cutting force as shown in Fig.6d.

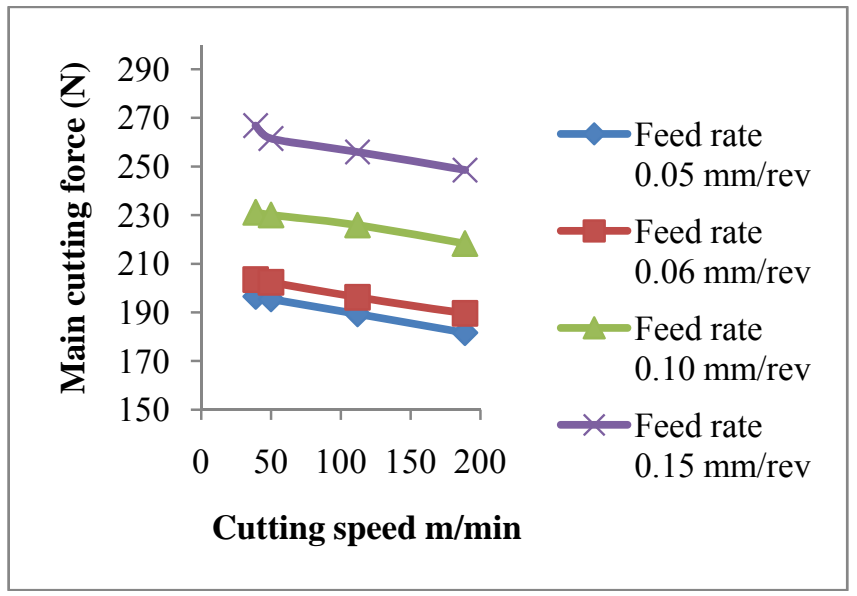

Fig. 6a.Effect of cutting speed on cutting force with different feed rate (Depth of cut $=0.4 \mathrm{~mm}$ and nose radius $=0.8 \mathrm{~mm}$ )

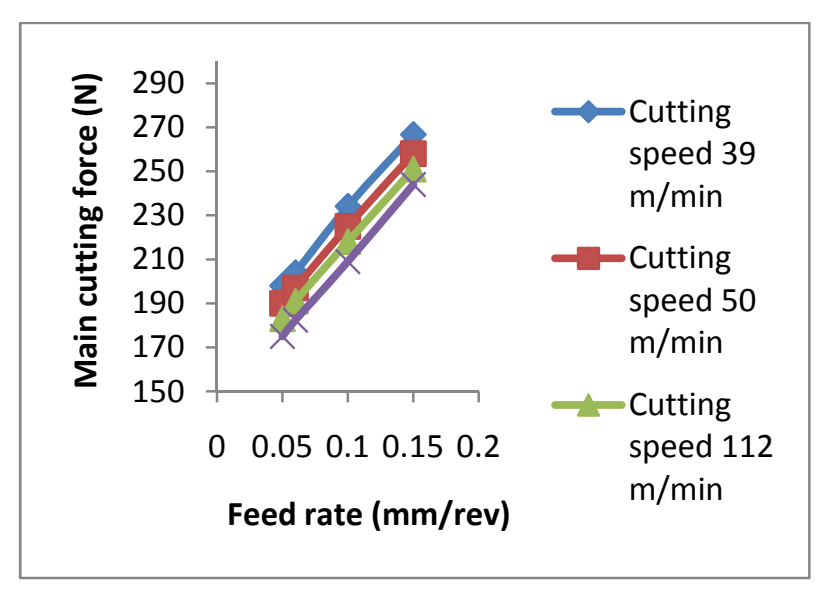

Fig. 6b Effect of feed rate on cutting force with different cutting speed (Depth of cut $=0.4 \mathrm{~mm}$ and nose radius $=0.8 \mathrm{~mm}$ )

\section{Conclusions}

1) Response surface methodology combined with the factorial design of experiment is found to be a successful technique to perform trend analysis of main cutting force with respect to various combinations of design variables (metal cutting velocity, feed rate, depth of cut and tool nose radius).

2) The first order and the second-order mathematical models are found to be adequately representing the main cutting force with experimental results. The established equations clearly show that the cutting speed, feed rate, depth of cut and tool nose radius were main influencing factors on the main cutting 
force. Main cutting force exhibits linear increasing trend, with the feed rate and depth of cut increasing from $(0.06-0.15 \mathrm{~mm} / \mathrm{rev}$ and $0.2-0.6 \mathrm{~mm}$ respectively), independent to cutting speed. It increased with increasing feed rate, depth of cut followed by tool nose radius but decreased with increasing the cutting velocity. Low value of main cutting force at high cutting speed $(189 \mathrm{~m} / \mathrm{min})$. High value of cutting force at high feed rate, depth of cut and tool nose radius. The interaction effect between cutting speed and tool nose radius and feed rate and depth of cut are reported easily, so, cutting force is higher at high level of feed rate, depth of cut and tool nose radius, but it is better when increasing cutting velocity $(189 \mathrm{~m} / \mathrm{min})$ with all levels of machining parameters.

3) The first-order and the second-order model predicting equations for main cutting force have been developed at 95\% confidence, using response surface methodology for machining EN-31 steel alloy with tungsten carbide inserts. The model developed in the research produces smaller errors and has satisfactory results. Therefore, the proposed model can be used to predict the corresponding cutting force of EN-31 steel at different parameters in turning.

4) The straight line obtained in the normal probability plot indicates a normal distribution of the residuals, validating the statistical analysis. The confirmation tests indicated that it is possible to optimize cutting force significantly by using the proposed statistical technique. It can be seen from the results that the important strength of factorial design of experiment is potential to build models and to gradually increase the complexity of the models if needed. In order to determine prediction model in turning processes, one can first use full factorial design in design of experiment technique a working space with high robustness, and then use regression analysis to generate a model of high stability.

5) The optimization of cutting parameters for machining of En-31 steel alloy is carried out using desirability based approach. The optimal conditions reduce the main cutting force in machining of EN-31 steel alloy within the parameters considered.

6) Response surface methodology design of experiments actually save time and cost of the experiments. From this design of experiments, useful information are collected such as developed the first order and the second order mathematical models of cutting force and counter plots.

7) The counter and the counter plot show the safe zone, to produce the optimum cutting force with optimum machining parameters. With the model equations obtained, a designer can subsequently select the best combination of design variables for achieving optimum or minimum cutting force during steel turning process. This eventually reduces the machining time, operation efforts, cost and save the cutting tools. A good combination among the cutting speed, feed rate, depth of cut and tool nose radius can achieve appropriate cutting force

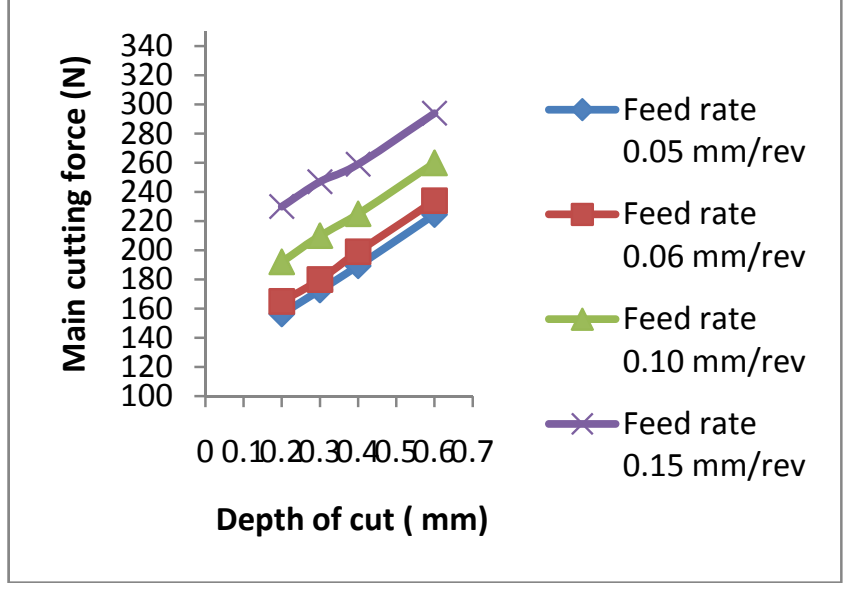

Fig. 6c. Effect of Depth of cu on cutting force with different feed rate (cutting speed $112 \mathrm{~m} / \mathrm{min}$ and nose radius $=0.8 \mathrm{~mm}$ )

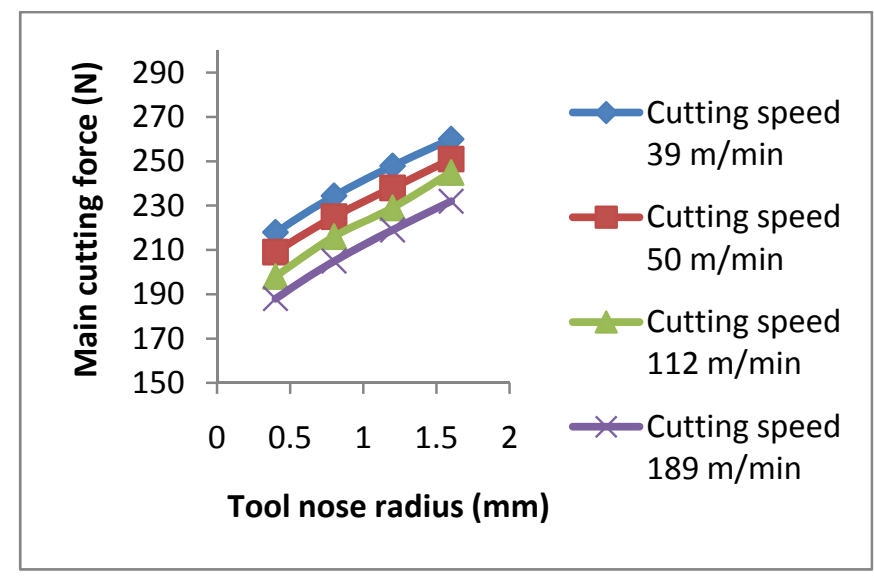

Fig. 6d. Effect of tool nose radius on cutting force with different cutting speed ( feed rate $0.10 \mathrm{~mm} / \mathrm{rev}$, depth of cut $0.4 \mathrm{~mm})$ 


\section{Acknowledgment}

The authors would like to express their deep gratitude to the Department of mechanical engineering of Aligarh Muslim University (AMU), for providing the laboratory facilities and financial support.

\section{References}

Abhang L. B. \& Hameedullah, M. ( 2009). Development of a Prediction model for Surface Roughness in Finish Turning of Alloy Steel, Mathematical and Computational Models: Recent Trends, Narosa Publishing House, New Delhi, India, 138-143

Alauddin, M. A., Mazid, M. A, EL Bardi, M. A. \& Hashmi, M. S. J. (1998). Cutting forces in the end milling of Inconel 718. Materials Process Technology, 77, 153-159.

Bhattacharyya, A. (1996). Metal cutting theory and Practice. New Central Book Agency (P) Ltd. Calcutta, 68-85.

Box GEP, (1978). Statistics for Experiments, John Willy and Sons Inc.USA, 38-46.

Chen, W. Y. (2000). Cutting forces and surface finish when machining medium hardness steel using CBN tools. International Machine Tools and Manufacture, 40, 455-466.

Chandra, M. T. G. Komaraiah, M. Kamala V, Prashanth, J.P. \& Bala, K. K. (2000). Condition monitoring of cutting force and power in a turning operation with tool wear, Sixteenth National Convention of Mechanical Engineers and National Seminar on Future Trends in Mechanical Engineering, 546-551.

David, J. P, \& Reis, P, (2004). Machinability study on composite (polyetheretherketone reinforced with $30 \%$ of glass fiber- peek GF30) using polycrystalline diamond (PCD) and cemented carbide tools (K20). International Journal of Advanced Manufacturing Technology, 23, 412-418.

Gunay, M. H., Korkut, I. Aslan, E. \& Seker, U., (2005). Experimental investigation of the effect of cutting tool rake angle on main cutting force. Journal of Material Processing Technology, 166, 44-49.

Kalpakjian, S. (1997). Manufacturing process for Engineering materials, Addison-Wesley, Menlo Park, California, USA, 3rd edition, 467-472

Komanduri R. (1982). Catastrophic shear instability in high speed machining of AISI 4330 steels. Transaction of ASME, Journal of Engineering, 104, 121-128.

Lin, W., Lee, B. \& Wu, C. (2001). Modeling the surface roughness and cutting force for turning. Journal of Material Processing Technology, 108, 286-293.

Luo, T. (1998). A neural network approach for force and counter error control in multi-dimensional end milling operations. International Journal of Machine Tools and Manufacture, 38, 1343-1359.

Lo K C., \& Chen N S S. (1977). Prediction of tool life in hot machining of alloy steels. International Journal of Production Research, 15, 47-63.

Minitab: Minitab version-15 Document, (2007), www.minitab.com.

Montgomery, D. C. (1991). Introduction to Quality Control, $2^{\text {nd }}$ ed., New York : John Wiley \& Sons.

Oraby, S. E. \& Hayhurst, D. R. (2004). Tool life determination based on the measurement of wear and tool force ratio variation. Journal of machine Tools and Manufacture, 44, 1261-1269.

Petropoulos, G. I., Ntziantzias, \& C Anghel, (2005). A predictive model of cutting force in turning using Taguchi and response surface techniques. First international conference at Athens, 6-9 July, 178-186.

Shaw, G. M. C.(1998). Metal cutting principles, Oxford University, Press, London, 219-223.

Sidda Reddy, B, Padmanabhan, G. \& Vijay kumar, K, (2008). Surface roughness prediction techniques for CNC turning, Asian Journal of Scientific Research 1(3), 256-264.

Trent, E. M. (1991). Metal cutting, Third Edition, Butterworth-Heinemann, Jordan Hill, 236-248.

Tzeng C-J. \& Yang, Y-K. (2008). Determination of optimal parameters for SKD11CNC turning process. Materials and Manufacturing Process, 23:363-368.

Wang, W, Kowloon S. H, \& Yang, S. H.(2005). A study on roughness of the micro end milling surface produced by a miniatured machine tool. Journal of Materials Processing Technology, 702-708. 